COLON CANCER

\title{
Detecting diminutive colorectal lesions at colonoscopy: a randomised controlled trial of pan-colonic versus targeted chromoscopy
}

\author{
D P Hurlstone, S S Cross, R Slater, D S Sanders, S Brown
}

Gut 2004;53:376-380. doi: 10.1136/gut.2003.029868

Background: Diminutive and flat colorectal lesions can be difficult to detect using conventional colonoscopic techniques. Previous data have suggested that pan-chromoscopy may improve detection rates. No randomised control trial has been performed examining detection rates of such lesions while controlling for extubation time and lavage effect.

Aim: We conducted a randomised controlled trial of pan-colonic chromoscopic colonoscopy for the detection of diminutive and flat colorectal lesions while controlling for extubation time and lavage effect. Methods: Consecutive patients attending for routine colonoscopy were randomised to either panchromoscopy using $0.5 \%$ indigo carmine (IC) or targeted chromoscopy (control group). A minimum diagnostic extubation time was set at eight minutes with controls undergoing a matched volume of saline wash.

Results: A total of 260 patients were randomised; 132 controls and 128 to pan-colonic chromoscopy. Extubation times did not differ significantly between the control (median 15 minutes (range 8-41)) and chromoscopy (median 17 minutes (range 8-39)) groups. The volume of IC used in the pan-chromoscopy group (median $68 \mathrm{ml}$ (range 65-90)) and normal saline used in the control group (69 $\mathrm{ml}$ (range 60-93))

See end of article for authors' affiliations

.....................

Correspondence to: Dr D P Hurlstone, 17 Alexandra Gardens, Lyndhurst Rd, Nether Edge, Sheffield S11 9DQ, UK; p.hurlstone@

shef.ac.uk

Accepted for publication 28 October 2003 did not differ significantly. There was a statistically significant difference between the groups regarding the total number of adenomas detected $(p<0.05)$ with significantly more diminutive $(<4 \mathrm{~mm})$ adenomas detected in the pan-chromoscopy group $(p=0.03)$. Pan-chromoscopy diagnosed more diminutive and flat lesions in the right colon compared with controls $(p<0.05)$, with more patients with multiple adenomas $(>3)$ detected using pan-chromoscopy $(p<0.01)$. Hyperplastic lesions were more commonly detected in the pan-chromoscopy group compared with controls $(p<0.001)$. More hyperplastic polyps were detected in the left colon ( $86 \%$ rectosigmoid) using chromoscopy compared with controls.

Conclusion: Chromoscopy improves the total number of adenomas detected and enhances the detection of diminutive and flat lesions. Importantly, eight diminutive lesions had foci of high grade dysplasia. Chromoscopy may benefit patients, assuming a high risk of colorectal cancer, and help in risk stratification and planning follow up colonoscopy intervals.
T he adenoma-carcinoma sequence described by Morson in 1968 has until now formed the rationale for the secondary prevention of colorectal cancer where early detection of precursor lesions will disrupt the pathogenic sequence and eliminate progression to invasive neoplastic disease. ${ }^{1}$ However, data now suggest that simple polypectomy of sessile and pedunculated lesions, although reducing the incidence of colorectal cancer (CRC), fails to prevent progression to carcinoma in up to $24 \%$ of cases. $^{2}$ It is therefore possible that a number of CRCs developing after polypectomy may derive from diminutive and flat lesions which may include a de novo pathogenic group. ${ }^{3}{ }^{4}$ Such lesions can be difficult to detect using conventional colonoscopic techniques showing only subtle changes at colonoscopy. ${ }^{5}$ Data suggest that up to $27 \%$ of small adenomas remain undiagnosed using conventional colonoscopy. ${ }^{7}$ Endoscopic techniques, which improve the frequency of adenoma detection, may therefore help optimise the potential of colonoscopy in the prevention of CRC.

Chromoscopic colonoscopy improves the detection of diminutive and flat colorectal lesions by highlighting subtle changes in mucosal topography, such as loss of vascular net pattern, focal pallor, fold convergence, and marginal irregularity. ${ }^{8}$ Chromoscopic methods are variable. Many authors have used "selective" chromoscopy only on the detection of a subtle mucosal irregularity diagnosed at conventional colonoscopy. ${ }^{9-12}$ Others have advocated total colonic chromoscopy by the use of an indigo carmine (IC) capsule taken orally prior to lavage colonic preparation. ${ }^{13}$ Brooker et al conducted the only randomised control trial of pan-mucosal chromoscopy using a colonic diffusion spray catheter which permitted complete mucosal coverage without requirements for excessive dye volumes or significant prolongation in procedure times. ${ }^{14}$ Both Mitooka and colleagues ${ }^{13}$ and Brooker' $\mathrm{s}^{14}$ data suggested colonic chromoscopy significantly increased the detection of diminutive neoplastic lesions, particularly in the right hemicolon. However, in the latter study extubation time was uncontrolled, with no control volume of normal saline used in the conventional colonoscopy group to remove the potential bias of the effect of lavage. ${ }^{14}$ Also, extubation times in the chromoscopy group were twice those of the conventional colonoscopy group. It is still unclear whether the advantages of pan-colonic chromoscopy are resultant from the technique or a reflection of the

Abbreviations: CRC, colorectal cancer; LGD, low grade dysplasia; $H G D$, high grade dysplasia; IC, indigo carmine; EMR, endoscopic mucosal resection 
withdrawal examination time. Two prospective studies in the UK have already shown both a significant prevalence and clinicopathological relevance of diminutive and flat colorectal lesions. ${ }^{912}$ These studies have implications for colorectal cancer screening, given the imminent introduction of a UK based programme. ${ }^{15}$

We therefore conducted a randomised controlled trial of pan-colonic chromoscopic colonoscopy for the detection of diminutive and flat colorectal lesions while controlling for extubation time and lavage effect.

\section{METHODS}

Total colonoscopy was performed on 260 consecutive patients using the Olympus C240 colonoscope (Olympus Optical Co., Tokyo, Japan) from June 2002 to May 2003 by two experienced endoscopists at the Royal Hallamshire and Northern General Hospitals Sheffield, UK. Full ethics approval for the study was granted from the South Sheffield Research Ethics Committee. Signed informed consent was obtained prior to all procedures. Caecal intubation was verified by identification of the appendix orifice, triradiate caecal fold, ileocaecal valve, and terminal ileal intubation with small bowel biopsy. Patients with known familial adenomatous polyposis, inflammatory bowel disease, known colorectal cancer, or inadequate bowel preparation did not enter the study. Patients were randomly allocated to targeted (control group) or pan-colonic IC $(0.5 \%)$ chromoscopy.

Bowel preparation comprised 2-4 litres of hypertonic polyethylene glycol solution (Kleanprep) 24 hours prior to the procedure. Quality of bowel preparation was graded by the endoscopist into one of three groups ${ }^{14}$ :

(1) good (near 100\% mucosal visualisation following aspiration or any liquid residue);

(2) fair (greater than $90 \%$ mucosal visualisation);

(3) poor (less than $90 \%$ mucosal visualisation).

Patients graded as "poor" preparation on these criteria were excluded from the study. Patients requesting conscious sedation received intravenous midazolam ( $1-10 \mathrm{mg}$ ) prior to intubation.

\section{Colonoscopic technique}

For patients randomised to the pan-chromoscopy group, a chromoscopy diffusion catheter (Olympus PW-5L-1) was used to apply a maximum of $150 \mathrm{ml}$ of $0.5 \%$ IC to the entire mucosa during withdrawal from the caecum. Chromoscopy was performed in $10 \mathrm{~cm}$ segments which were then reinspected following aspiration of any excess IC forming pools in the colon. Patients randomised to the control group received conventional colonoscopy with particular attention to subtle mucosal signs such as the presence of erythema, focal pallor, haemorrhagic spots, absence of vascular network pattern, discrete mucosal unevenness, or deformity. ${ }^{5}$ In this group, patients underwent segmental examination of the colon as in the pan-chromoscopy group but using a controlled volume of normal saline solution to a maximum of $150 \mathrm{ml}$ applied through an identical diffusion catheter. Selective chromoscopy (2-5 $\mathrm{ml}$ of IC flushed down the side port of the colonoscope followed by a $20 \mathrm{ml}$ air "push") was permitted to further delineate suspected mucosal lesions which had been identified by observing the mucosal signs (described above) without the prior use of chromoscopy.

A minimum diagnostic extubation time from the caecum to the anus (excluding that required for interventional procedures) was set at eight minutes for all patients entering the study. Total diagnostic extubation times were recorded for all procedures.

\section{Endoscopic classification and resection of lesions}

Pedunculated lesions were defined as those with a distinct pedicle and sessile as raised lesions with no evidence of a stalk or pedicle where the diameter did not exceed twice the height. ${ }^{16}$ Flat lesions were defined as mucosal change with a flat or slightly rounded surface with a height of less than half the diameter of the lesion. ${ }^{17}$ The diameter of each lesion was estimated using a standard fully open biopsy forcep $(4 \mathrm{~mm})$ with the height estimated by placing the closed forcep tip adjacent to the lesion $(2.1 \mathrm{~mm})$ (Bard Inc., USA). Morphology, size, and anatomical location of all lesions were documented.

Sessile and flat lesions less than $20 \mathrm{~mm}$ in diameter were resected using endoscopic mucosal resection (EMR) with the saline snare assisted technique described by Karita and colleagues. ${ }^{18}$ A barbed snare (Olympus Keymed UK N110) was used for all resections with an "endo-coag mode" $25 \mathrm{~W}$ ERBE diathermy (ERBE Medical UK-ICC200). Lesions which failed to lift were cold biopsied only and a submucosal Indian ink tattoo applied adjacent to the lesion for future localisation. Lesions showing a depressed morphology larger than $10 \mathrm{~mm}$ diameter were also cold biopsied only as they demonstrate a high incidence of invasive neoplasia. ${ }^{9}{ }^{19}$ Lesions in excess of $20 \mathrm{~mm}$ diameter (without depression) were resected by piecemeal EMR or cold biopsies if anatomical problems made endoscopic resection impossible. Pedunculated polyps were removed by simple snare polypectomy. Lesions smaller than $4 \mathrm{~mm}$ diameter were treated by hot biopsy.

\section{Histopathological analysis}

Two experienced designated pathologists examined all retrieved tissue. Specimens were immediately fixed in 10\% buffered formalin solution and stained with haematoxylineosin. Dysplasia was defined according to the Vienna criteria as either low grade (LGD) or high grade (HGD). ${ }^{20}$ Neoplastic cellular proliferation extending into the deep submucosal layer 3 or beyond to the muscularis propria was classed as invasive cancer. ${ }^{20}$ Lesions were classified as early CRC when intra- or submucosal carcinoma was present only, with no vertical extension into the muscularis propria. $^{20}$

\section{Statistical analysis}

A sample size calculation was based on the analysis by Brooker et al. ${ }^{14}$ We assumed from historical data that the mean number of adenomas per patient in the control group would be 0.36 (SD 0.3). A clinically significant increase in adenoma detection using pan-chromoscopy was set at $30 \%$. Using these parameters, we calculated that a minimum of 118 patients in both the control and chromoscopy groups were required to gain significance $(\times$ level $80 \%)$. Statistical differences were analysed by $\chi^{2}$ tests of independence, the Mann-Whitney $U$ test, and Fisher's exact test. A p value of less than 0.05 was considered statistically significant. All calculations were made using the SPSS statistical package for Windows 1998 (Microsoft Corporation USA). The University of Sheffield Statistics Unit provided statistical advice and support.

\section{RESULTS}

A total of 260 patients were recruited to the study. Patient demographics and indications for colonoscopy are shown in tables 1 and 2, respectively. The pan-chromoscopy group included 128 patients, of whom 58 (45\%) were male (median age 58 years (range 22-92)). The control group included 132 patients (61 males $(46 \%)$; median age 53 years (range 2389)). There were no statistically significant differences between the pan-chromoscopy and control groups with respect to sex, age, indications for colonoscopy, or quality 


\begin{tabular}{|c|c|c|c|}
\hline & $\begin{array}{l}\text { Control } \\
\text { group }\end{array}$ & $\begin{array}{l}\text { Chromoscopy } \\
\text { group }\end{array}$ & $\mathrm{p}$ Value \\
\hline n & 132 & 128 & \\
\hline \multicolumn{4}{|l|}{ Age (y) } \\
\hline Median & 53 & 58 & NSt \\
\hline Range & $23-89$ & $22-92$ & $\mathrm{NS}^{*}$ \\
\hline Prep score (median (range)) & $3(2-3)$ & $3(2-3)$ & NSt \\
\hline
\end{tabular}

of bowel preparation. Twenty three cases were excluded prior to randomisation due to inadequate bowel preparation $(\mathrm{n}=14)$, incomplete colonoscopy $(\mathrm{n}=5)$, obstructing tumour mass $(\mathrm{n}=2)$, and procedural diagnosis of severe colitis $(n=2)$. There were no immediate $(<24$ hours) or delayed ( $>24$ hours) complications.

\section{Lesion demographics}

A total of 289 lesions were diagnosed in 138 patients. The median number of lesions detected was 0 (range 0-24). Tissue was retrieved for histological analysis from 288 (99\%) lesions. One hundred and three lesions (36\%) were diagnosed in the control group compared with 185 (64\%) lesions in the pan-chromoscopy group. Hyperplastic histology was reported in $117(41 \%)$ lesions with $45(38 \%)$ and $72(62 \%)$ being present in the control and pan-chromoscopy groups, respectively. Fifty nine hyperplastic lesions $(51 \%)$ were flat with 58 $(49 \%)$ being protuberant. Neoplastic lesions accounted for the remaining 170 (59\%) lesions where 57 (33\%) and 112 $(66 \%)$ were present in the control and pan-chromoscopy groups, respectively. Of the neoplastic lesions identified, 168 $(98 \%)$ were adenomas. Seventy six $(45 \%)$ of all adenomas were flat with 92 (55\%) being protuberant. One flat and one protuberant lesion had evidence of carcinoma in situ. No invasive carcinomas were identified in this cohort. Anatomical location, morphology, and histological analysis of the lesions are summarised in table 3.

The number of hyperplastic polyps detected in the panchromoscopy group was significantly higher than that in the control group $(p<0.001)$. There was also a significant difference between the groups regarding the total number of adenomas detected $(\mathrm{p}<0.05)$. A significantly higher number of diminutive $(<4 \mathrm{~mm})$ and flat adenomas were detected in the pan-chromoscopy group compared with controls $(\mathrm{p}<0.01)$. Importantly, eight flat lesions (mean diameter $6.2 \mathrm{~mm}$; range $5-8 \mathrm{~mm}$ ) in the pan-chromoscopy group had HGD histologically. Three diminutive adenomas in this group also had HGD with one being predominantly villous. The remaining diminutive lesions all had LGD appearances histologically. These results are summarised in table 4 .

Analysis of lesions according to anatomical site showed that significantly more hyperplastic polyps were detected in the left colon (86\% within the rectosigmoid) using pan-chromoscopy compared with controls $(\mathrm{p}<0.04)$. Panchromoscopy also diagnosed more right hemicolonic diminutive and flat lesions compared with the control group $(\mathrm{p}<0.05)$. More patients with multiple adenomas $(>3)$ were detected using pan-chromoscopy $(n=13)$ compared with controls $(\mathrm{n}=4)(\mathrm{p}<0.01)$.

Extubation times did not differ significantly between the control and pan-chromoscopy groups (median 15 minutes (range 8-41) v 17 minutes (8-39), respectively) $(\mathrm{p}>0.1)$. Median volume of IC used in the pan-chromoscopy group was $68 \mathrm{ml}$ (range 65-90). Within the control group, a median of $69 \mathrm{ml}$ of normal saline was used (range 60-93). No significant difference was observed in the volume of IC and normal saline used between the pan-chromoscopy and control groups.

\section{DISCUSSION}

Following the initial description of colonic chromoscopy by Tada and colleagues, ${ }^{21}$ the technique has been applied to many aspects of colonoscopy. Many authors report that chromoscopy is helpful for the detection and detailed morphological assessment of flat and depressed colorectal lesions. ${ }^{10} 12192223$ Kudo et al refined the technique further, combining colonic chromoscopy with high magnification colonoscopy for the in vivo prediction of histology (optical biopsy technique). ${ }^{24}$ Saitoh and other groups have used both colonic chromoscopy and high magnification colonoscopy as an in vivo staging tool for the assessment of flat and depressed colorectal neoplasia. ${ }^{25-27}$ Kiesslich et al showed that pan-colonic chromoscopy using methylene blue also increased the detection rates of intraepithelial neoplasia in colitis surveillance threefold, ${ }^{28}$ data validated by our group. ${ }^{29}$ However, only one randomised controlled trial has assessed detection rates of colorectal lesions using pan-colonic IC chromoscopy. ${ }^{14}$ This study did not control for diagnostic extubation time between the pan-chromoscopy and targeted chromoscopy control group and also did not control for the lavage effect encountered when using chromoscopy. ${ }^{14}$ Although showing a significant increase in diminutive adenoma detection, ${ }^{14}$ these data were unable to clarify the potential benefits of chromoscopy in routine clinical practice.

In our study, pan-colonic chromoscopy did significantly improve the total number of adenomatous lesions detected and significantly improved detection rates of diminutive and flat adenomas. Despite their small size, 3\% of diminutive lesions in Brooker's cohort had moderate dysplastic histology with $2 \%$ having villous architecture. ${ }^{14}$ Our data showed a similar prevalence, with three HGD diminutive adenomas diagnosed with one villous adenoma. All are therefore significant lesions at high risk of progression to carcinoma. The three diminutive HGD adenomas were present in the right colon where pan-chromoscopy in our series diagnosed more right hemicolonic diminutive and flat lesions compared

\begin{tabular}{|c|c|c|c|}
\hline Indication & Control group & Chromoscopy group & p Value \\
\hline $\mathrm{n}$ & 132 & 128 & \\
\hline Polyp surveillance & 70 & 66 & NS \\
\hline Post surgical cancer surveillance & 33 & 34 & NS \\
\hline Iron deficiency anaemia & 16 & 14 & NS \\
\hline Rectal bleeding & 3 & 7 & NS \\
\hline Change in bowel habit & 2 & 1 & NS \\
\hline Diarrhoea & 6 & 5 & NS \\
\hline Other indication & 2 & 1 & NS \\
\hline Total & 132 & 128 & \\
\hline
\end{tabular}

NS, not significant. 
Table 3 Relationship between morphological type, anatomical location, and histology for lesions diagnosed in the control and pan-chromoscopy groups

\begin{tabular}{|c|c|c|c|c|c|c|c|c|c|c|c|}
\hline \multirow[b]{2}{*}{ Morphology } & \multirow[b]{2}{*}{$\begin{array}{l}\text { Anatomical } \\
\text { location }\end{array}$} & \multicolumn{5}{|l|}{ Control group } & \multicolumn{5}{|c|}{ Pan-chromoscopy group } \\
\hline & & Hyperplastic & $\begin{array}{l}\text { Adenoma } \\
\text { LGD }\end{array}$ & $\begin{array}{l}\text { Adenoma } \\
\text { HGD }\end{array}$ & $\begin{array}{l}\text { In situ } \\
\text { carcinoma }\end{array}$ & $\begin{array}{l}\text { Invasive } \\
\text { carcinoma }\end{array}$ & Hyperplastic & $\begin{array}{l}\text { Adenoma } \\
\text { LGD }\end{array}$ & $\begin{array}{l}\text { Adenoma } \\
\text { HGD }\end{array}$ & $\begin{array}{l}\text { In situ } \\
\text { carcinoma }\end{array}$ & $\begin{array}{l}\text { Invasive } \\
\text { carcinoma }\end{array}$ \\
\hline \multirow[t]{3}{*}{ Flat } & Right colon & 3 & 12 & 3 & 0 & 0 & 8 & 25 & 11 & 1 & 0 \\
\hline & Left colon & 28 & 6 & 1 & 0 & 0 & 20 & 12 & 6 & 0 & 0 \\
\hline & Total & 31 & 18 & 4 & 0 & 0 & 28 & 37 & 17 & 1 & 0 \\
\hline \multirow[t]{3}{*}{ Protuberant } & Right colon & 4 & 7 & 2 & 0 & 0 & 15 & 15 & 2 & 0 & 0 \\
\hline & Left colon & 10 & 24 & 2 & 1 & 0 & 29 & 37 & 3 & 0 & 0 \\
\hline & Total & 14 & 31 & 4 & 1 & 0 & 44 & 52 & 5 & 0 & 0 \\
\hline
\end{tabular}

with controls. Also, the number of hyperplastic lesions detected by pan-chromoscopy was significantly higher than the control group, with $86 \%$ being present within the rectosigmoid. These data confirm those observed by Brooker and colleagues. ${ }^{14}$

Importantly, pan-chromoscopy increased detection of patients with multiple adenomas (>3) who, according to the data of Atkin and colleagues ${ }^{30}$ and Winawer and colleagues, ${ }^{31}$ are a group at high risk of developing advanced neoplasia at follow up. We additionally showed that significantly more flat and diminutive adenomas were present in the right colon compared with controls, which is consistent with Woolfson ${ }^{32}$ and Hofstad's ${ }^{33}$ reporting of a proximal shift in adenoma distribution. Brooker's data also confirm this observation. ${ }^{14}$

There are limitations to our study. Two experienced endoscopists who have trained in Japanese colonoscopic diagnostic techniques performed all examinations. In this scenario, detection rates of lesions within the control group may have been increased. As we used endoscopists with additional training, we are unable to hypothesise if pan-chromoscopy would improve overall adenoma detection rates compared with "conventionally" trained UK endoscopists. Alternatively, this approach ensured that the detection rates within the control and chromoscopy groups were not a result of the endoscopist's experience. However, we would suggest that although colonic chromoscopy is important as an adjunctive diagnostic tool, further training and education would be helpful for many practitioners. Indeed, should the clinical evidence for chromoscopy and magnification "zoom" endoscopy become apparent in long term follow up studies, issues of additional training will need to be addressed within the UK.

The increase in detection rate of lesions using panchromoscopy, although improving the yield of clinically relevant lesions, also results in an increased number of hyperplastic and LGD adenomatous lesions being diagnosed. ${ }^{14}$ The risk of progression to carcinoma in both of these groups requires clarification with long term follow up studies. High magnification chromoscopic colonoscopy has been used as an in vivo optical biopsy tool to distinguish non-neoplastic, neoplastic, and invasive characteristics in polyps but with variability in reported sensitivity and specificity. ${ }^{24} 3435$ However, further prospective studies using this technology are required as it may offer a useful tool to the endoscopist when deciding "on table" management policy such as biopsy, polypectomy, or EMR. ${ }^{36}$ It may therefore be possible to lower the number of biopsies taken from non-neoplastic or low risk lesions while allowing selective resection of lesions considered clinically significant. Such a strategy may reduce the number of resection associated complications ${ }^{37}$ and reduce the secondary burden to histopathology services.

In conclusion, disruption of the adenoma-carcinoma sequence by endoscopic polypectomy has been shown to reduce the incidence of CRC. ${ }^{2}$ Despite reduction rates of 76$90 \%$ compared with reference populations in the National Polyp Study, five interval cancers were diagnosed. ${ }^{2}$ The Veterans Affairs study of 32702 patients demonstrated a lower cancer preventative rate of $50 \%$ although not all cases received total colonoscopy. ${ }^{38}$ Evidence suggests that between $15 \%$ and $27 \%$ of lesions remain undiagnosed at colonoscopy, even by experienced practitioners. ${ }^{39}$ Many reasons can account for these findings. Inadequate bowel preparation may result in suboptimal mucosal views, with flat and diminutive lesions being reported by many authors as difficult to detect with conventional colonoscopic techniques. $^{910} 19$ Traditional colonoscopic training within the UK has also focused on the diagnosis of exophytic or polypoid lesions with less emphasis given to flat and diminutive colorectal lesions. However, data from the UK now suggest that such lesions have a significant prevalence and malignant potential in certain morphological subgroups. ${ }^{912}$ It is therefore possible that some cancers may develop from diminutive and flat colorectal lesions where failure to diagnose and treat ultimately leads to invasive neoplasia. Colonic chromoscopy may improve our detection of such lesions. In routine practice, chromoscopy may benefit patients, assuming a high risk of CRC, and may be a helpful tool used at index colonoscopy when applied to risk stratification and planning follow up colonoscopy intervals.

Table 4 Summary of patient numbers and lesions diagnosed in the control and panchromoscopy groups

\begin{tabular}{lllc}
\hline & Control group & Chromoscopy group & p Value \\
\hline Patients with $>1$ lesion & 55 & 83 & $<0.01^{*}$ \\
Patients with $>1$ hyperplastic lesion & 20 & 67 & $0.02^{*}$ \\
Patients with $\geqslant 3$ adenomas & 4 & 13 & $<0.01^{*}$ \\
Patients with HGD adenoma or beyond & 6 & 22 & $0.006^{*}$ \\
\hline
\end{tabular}

HGD, high grade dysplasia.

*Fisher's exact $\chi^{2}$ test. 


\section{ACKNOWLEDGEMENTS}

Grant support was obtained from the Smith and Nephew Research Foundation (UK), BRET Research Foundation (UK), Butterfield "Sasakawa" Research Foundation (UK), Mason Medical Research Foundation (UK), Keymed (UK), and Special Trustees to the Sheffield Central University Hospitals.

\section{Authors' affiliations}

D P Hurlstone, D S Sanders, Gastroenterology and Liver Unit, Royal Hallamshire Hospital, Sheffield, UK

S S Cross, Academic Unit of Pathology, Section of Oncology and Pathology, Division of Genomic Medicine, University of Sheffield Medical School, Sheffield, UK

R Slater, S Brown, Department of Surgery, Northern General Hospital NHS Trust, Sheffield, UK

\section{REFERENCES}

1 Morson BC. Precancerous and early malignant lesions of the large intestine. Br J Surg 1968;55:725-31.

2 Winawer SJ, Zauber AG, Ho MN, et al. Prevention of colorectal cancer by colonoscopic polypectomy. The National Polyp Study Workgroup. NEngl J Med 1993;329:1977-81

3 Kudo S, Tamura S, Hirota S, et al. The problem of de novo colorectal carcinoma. Eur J Cancer 1995; 31:1118-20.

4 Kudo S, Kashida H, Nakajima T, et al. Endoscopic diagnosis and treatment of early colorectal cancer. World J Surg 1997;21:694-701.

5 Kudo S, Kashida H, Tamura T, et al. Colonoscopic diagnosis and management of nonpolypoid early colorectal cancer. World J Surg 2000;24:1081-90.

6 Hurlstone DP, Fujii T, Lobo AJ. Early detection of colorectal cancer using highmagnification chromoscopic colonoscopy. Br J Surg 2002;89:272-82.

7 Hixson LJ, Fennerty MB, Sampliner RE, et al. Prospective blinded trial of the colonoscopic miss-rate of large colorectal polyps. Gastrointest Endosc 1991:37:125-7.

8 Keisslich $\mathbf{R}$, von Bergh $M$, Hahn $M$, et al. Chromoendoscopy with indigocarmine improves the detection of adenomatous and nonadenomatous lesions in the colon. Endoscopy 2001;33:1001-3.

9 Rembacken BJ, Fujii T, Cairns A, et al. Flat and depressed colonic neoplasms: a prospective study of 1000 colonoscopies in the UK. Lancet 2000;355:1211-14.

10 Tsuda S, Veress B, Toth E, et al. Flat and depressed colorectal tumours in a southern Swedish population: a prospective chromoendoscopic and histopathological study. Gut 2002;51:550-5.

11 Wolber RA, Owen DA. Flat adenoma of the colon. Hum Pathol 1991;22:70-4.

12 Hurlstone DP, Cross SS, Adam I, et al. A prospective clinicopathological and endoscopic evaluation of flat and depressed colorectal lesions in the UK. Am J Gastroenterol 2003;98:2543-9.

13 Mitooka H, Fujimori T, Maeda S, et al. Minute flat depressed neoplastic lesions of the colon detected by contrast chromoscopy using an indigo carmine capsule. Gastrointest Endosc 1995;41:453-9.

14 Brooker JC, Saunders BP, Shah SG, et al. Total colonic dye-spray increases the detection of diminutive adenomas during routine colonoscopy: a randomized controlled trial. Gastrointest Endosc 2002;56:333-8.

15 Joint Position Statement by the British Society of Gastroenterology, The Royal College of Physicians and the Association of Coloproctology of Great Britain and Ireland. Colorectal cancer screening in the UK. Gut 2000:46:746-8.

16 Lambert R, Provenzale D, Ectors N, et al. Early diagnosis and prevention of sporadic colorectal cancer. Endoscopy 2001;33:1042-64.

17 Muto T, Kamiya J, Sawada T, et al. Small 'flat' adenoma' of the large bowel with special reference to its clinicopathological feature. Dis Colon Rectum 1985;28:857-61.
18 Karita M, Tada M, Okita K, et al. Endoscopic therapy for early colon cancer: the strip biopsy resection technique. Gastrointest Endosc 1991;37:128-32.

19 Adachi M, Okinaga K, Muto T. Flat adenoma of the large bowel: reevaluation with special reference to central depression. Dis Colon Rectum 2000;43:782-7

20 Schlemper RJ, Riddell RH, Kato Y, et al. The Vienna classification of gastrointestinal neoplasia. Gut 2000;47:251-5.

21 Tada M, Misaki F, Kawai K. A new approach to the observation of minute changes of the colonic mucosa by means of magnifying colonoscope, type CFMB-M (Olympus). Gastrointest Endosc 1978;24:146-7.

22 Sawada T, Hojo K, Moriya Y. Colonoscopic management of focal and early colorectal carcinoma. Bailliere's Clin Gastroenterol 1989:3:627-45.

23 Tanaka S, Haruma K, Ito $M$, et al. Detailed colonoscopy for detecting early superficial carcinoma: recent developments. J Gastroenterol 2000;35(suppl 12):121-5.

24 Kudo S, Rubio CA, Teixeira CR, et al. Pit pattern in colorectal neoplasia: endoscopic magnifying view. Endoscopy 2001;33:367-73.

25 Saitoh Y, Obara T, Watari J, et al. Invasion depth diagnosis of depressed type early colorectal cancers by combined use of videoendoscopy and chromoendoscopy. Gastrointest Endosc 1998:48:362-70.

26 Nagata S, Tanaka S, Haruma K, et al. Pit pattern diagnosis of early colorectal carcinoma by magnifying colonoscopy: clinical and histological implications. Int J Oncol 2000; 16:927-34.

27 Tanaka S, Haruma K, Teixeira CR, et al. Endoscopic treatment of submucosal invasive colorectal carcinoma with special reference to risk factors for lymph node metastasis. J Gastroenterol 1995;30:710-17.

28 Kiesslich R, Fritsch J, Holtmann M, et al. Methylene blue-aided chromoendoscopy for the detection of intraepitheial neoplasia and colon cancer in ulcerative colitis. Gastroenterology 2003;124:880-8.

29 Hurlstone DP, McAlindon ME, Sanders DS, et al. Further validation of highmagnification-chromoscopic colonoscopy for the detection of intraepithelial neoplasia and colon cancer in ulcerative colitis. Gastroenterology 2004 (in press).

30 Atkin WS, Morson BC, Cuzick J. Long-term risk of colorectal cancer after excision of rectosigmoid adenomas. N Engl J Med 1992;326:658-62.

31 Winawer SJ, Zauber AG, O'Brien MJ. Randomised comparison of surveillance intervals after colonoscopic removal of newly diagnosed adenomatous polyps. The National Polyp Study Workgroup. N Engl J Med 1993;328:901-6.

32 Woolfson IK, Eckholdt GJ, Wetzel CR, et al. Usefulness of performing colonoscopy one year after endoscopic polypectomy. Dis Colon Rectum 1990;33:389-93

33 Hofstad B, Vatn M, Larsen S, et al. Growth of colorectal polyps: recovery and evaluation of unresected polyps of less than $10 \mathrm{~mm}, 1$ year after detection. Scand J Gastroenterol 1994;29:640-5.

34 Tung SY, Wu CS, Su MY. Magnifying colonoscopy in differentiating neoplastic from nonneoplastic colorectal lesions. Am J Gastroenterol 2001;96:2628-32.

35 Togashi K, Konishi F, Ishizuka T, et al. Efficacy of magnifying endoscopy in the differential diagnosis of neoplastic and non-neoplastic polyps of the large bowel. Dis Colon Rectum 1999;42:1602-8.

36 Hurlstone DP, Cross SS, Adam I, et al. Efficacy of high magnification chromoscopic colonoscopy for the diagnosis of neoplasia in flat and depressed lesions of the colorectum: a prospective analysis. Gut 2004:53:284-90.

37 Waye JD, Kahn O, Auerbach ME. Complications of colonoscopy and flexible sigmoidoscopy. Gastrointest Endosc Clin N Am 1996:6:343-77.

38 Muller AD, Sonnenberg A. Prevention of colorectal cancer by flexible endoscopy and polypectomy. A case-control study of 32,702 veterans. Ann Intern Med 1995; 123:904-10.

39 Rex DK, Cutler CS, Lemmel GT, et al. Colonoscopic miss rates of adenomas determined by back-to-back colonoscopies. Gastroenterology 1997; 112:24-8.

40 Hixson L, Fennerty MB, Sampliner RE, et al. Prospective study of the frequency and size distribution of polyps missed by colonoscopy. J Natl Cancer Inst 1990;82:1769-72. 